
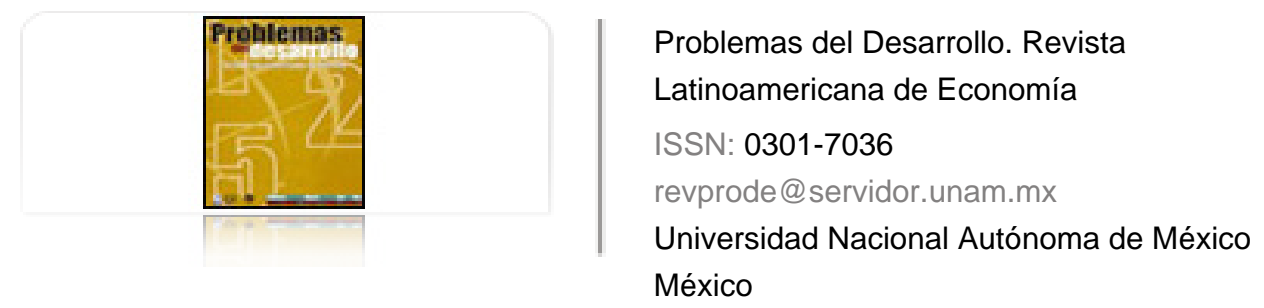

Huerta Quintanilla, Rogelio

EL INGRESO CIUDADANO EN MÉXICO: IMPACTO Y VIABILIDAD

Problemas del Desarrollo. Revista Latinoamericana de Economía, vol. 40, núm. 159, octubre-

diciembre, 2009, pp. 85-100

Universidad Nacional Autónoma de México

Distrito Federal, México

Disponible en: http://www.redalyc.org/articulo.oa?id=11820103005

- Cómo citar el artículo

- Número completo

- Más información del artículo

Página de la revista en redalyc.org

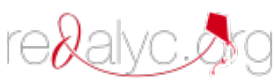

Sistema de Información Científica

Red de Revistas Científicas de América Latina, el Caribe, España y Portugal Proyecto académico sin fines de lucro, desarrollado bajo la iniciativa de acceso abierto 


\title{
EL INGRESO CIUDADANO EN MÉXICO: IMPACTO Y VIABILIDAD
}

\author{
Rogelio Huerta Quintanilla*
}

Fecha de recepción: 22 de mayo de 2009. Fecha de aceptación: 13 de agosto de 2009.

\section{Resumen}

Dada la situación crítica de la economía mexicana y su repercusión negativa sobre la mayoría más desprotegida de la población, en este artículo se propone una medida de política pública, denominada ingreso ciudadano universal o renta básica, para redistribuir el ingreso, tratar de eliminar la pobreza extrema, reactivar el mercado interno, reestructurar la planta productiva del país y darle a México una nueva perspectiva de desarrollo.

El ingreso ciudadano universal es una medida de intervención gubernamental en la parte distributiva del ingreso nacional, cuyo propósito es que toda persona, tan sólo por el hecho de vivir en México, se sienta segura de que va a recibir del gobierno un ingreso que le permitirá satisfacer sus necesidades básicas. Esta subvención se otorga sin condición alguna.

Palabras clave: ingreso ciudadano universal, estancamiento económico, insuficiencia de demanda, crecimiento económico y redistribución del ingreso.

\begin{abstract}
Given the critical situation of the Mexican economy and the negative repercussion this has on the least protected mass of the population, the present article proposes a public policy measure known as the universal citizen's income or the basic wage, to redistribute income, in an effort to eliminate extreme poverty, reactivate the domestic market, restructure the country's productive facilities and give Mexico a new development perspective.

The universal citizen's income is a mode of government intervention in the area of national income distribution, whereby every person, simply by virtue of their residence in Mexico, is ensured of receiving an income from the government, making it possible to satisfy their basic needs. This subvention is granted without any conditions.

Key words: universal citizen's income, economic stagnation, insufficiency of demand, economic growth and income redistribution.
\end{abstract}

* Profesor de tiempo completo de la Facultad de Economía de la UNAM. Área de Teoría Económica de la División de Estudios Profesionales. Correo electrónico: rhuerta@ servidor.unam.mx 


\section{Résumé}

Étant donné la situation critique de l'économie mexicaine et sa répercussion négative sur la majorité défavorisée de la population, dans cet article il est proposé une mesure de politique publique, dénommée revenu citoyen universel ou rente de base, pour redistribuer le revenu, tenter d'éliminer la pauvreté extrême, réactiver le marché interne, restructurer le système productif du pays et redonner au Mexique une perspective de développement.

Le revenu citoyen universel est une mesure d'intervention gouvernementale dans la partie distributive du revenu national, dont l'objet est que toute personne, pour le simple fait de vivre au Mexique, puisse se sentir sûre de recevoir du gouvernement un revenu qui lui permette de satisfaire ses besoins élémentaires. Ce subside s'octroie sans aucune condition.

Mots clés: revenu citoyen universel, stagnation économique, insuffisance de demande, croissance économique et redistribution du revenu.

\section{Resumo}

Dada a situação crítica da economia mexicana e sua repercussão negativa sobre a maioria mais desprotegida da população, neste artigo propõe-se uma medida de política pública, denominada salário cidadão universal ou renda básica, para redistribuir o ingresso, tratar de eliminar a pobreza extrema, reativar o mercado interno, reestruturar a planta produtiva do país e dar ao México uma nova perspectiva de desenvolvimento.

O salário cidadão universal é uma medida de intervenção governamental na parte distributiva do ingresso nacional, cujo propósito é que toda pessoa, pelo simples fato de viver no México, se sinta segura de que vai receber do governo um ingresso que lhe permitirá satisfazer suas necessidades básicas. Esta subvenção se outorga sem condição alguma.

Palavras-chave: salário cidadão universal, estancamento econômico, insuficiência de demanda, crescimento econômico e redistribuição do ingresso. 
Introducción

$\varepsilon$

1 ingreso ciudadano (IC) es una propuesta que tiene entre sus objetivos comba-

tir de raíz la pobreza y sentar las bases para construir una sociedad más equita-

tiva y justa, al tiempo que se dirige la economía hacia rumbos más sólidos para el conjunto de los habitantes.

Los profundos cambios económicos provocados por la revolución tecnológica han permitido a los seres humanos aumentar su capacidad para producir riqueza con grandes ahorros de capital y trabajo. La automatización y la robotización de los procesos productivos han conseguido que una creciente masa de riqueza se obtenga con una decreciente cantidad de trabajo. Esto, junto con el descenso del ritmo de crecimiento económico y la pérdida del poder de negociación de los trabajadores, ha traído como consecuencia una tendencia decreciente en las remuneraciones y en el pago de salarios y, por ende, una reducción en la capacidad de compra de la población trabajadora, junto con crecientes índices de desempleo, subempleo y empleo precario; todo ello ha redundado en un aumento de la pobreza y de la miseria absoluta.

Considerando la evolución anterior y con la experiencia de que las políticas tradicionales de los gobiernos para aumentar el nivel de empleo han resultado, cuando menos, insuficientes, y de que el estímulo a la inversión privada y la búsqueda de una mayor productividad podrían afectar negativamente al empleo, se hace necesario discutir una alternativa que supere los marcos de las políticas convencionales.

El IC tiene muchos aspectos, y aunque en este ensayo no se revisarán todos, para tener una visión amplia de su perspectiva es pertinente citar a uno de sus primigenios impulsores, para tratar de ubicar las dimensiones de esta iniciativa.

Una de las funciones de la asignación universal es... hacer del derecho al desarrollo de las facultades de cada uno el derecho incondicional a una autonomía que trasciende su función productiva y existe por y para ella misma en el plano moral (autonomía de juicio de valor), político (autonomía de la decisión relativa al bien común), cultural (invención de estilos de vida, modelos de consumo y artes de vivir), existencial (capacidad de hacerse cargo en lugar de abandonar a los expertos y a las autoridades la preocupación de decidir lo que es bueno para nosotros). (Gorz, 2003: 98-99.)

De acuerdo con este autor, la autonomía que una persona puede alcanzar cuando cuenta con una fuente de ingresos que le asegure su sobrevivencia, es la plataforma que le permitirá desarrollar las actividades más creativas, de respeto y solidaridad y de convivencia social. Además, se puede postular que esa mayor autonomía económica puede facilitar una aceptación por parte de los trabajadores de un progreso técnico gradual. No obstante que se reconoce que el IC abarca muchas y muy variadas esferas 
de la realidad, en este trabajo sólo se va a contemplar una: la referente a su impacto y viabilidad económica en México.

Cabe insistir en que el IC tiene muchas facetas. Puede estudiarse desde el punto de vista de los derechos sociales y de los cambios en las condiciones jurídicas de los individuos. Puede analizarse desde la perspectiva de la solidaridad social y los fenómenos de competencia y cooperación entre los seres humanos. También pueden verse sus efectos sobre las relaciones morales y éticas y sopesarse las trayectorias filosóficas que lo fundamentan. Sin embargo, el presente artículo sólo se ocupa de revisar los efectos de la implantación del ingreso ciudadano en las condiciones macroeconómicas de México, en particular sus consecuencias sobre la inflación y el comercio exterior.

Para lograr establecer el IC, es obvio que tanto en México, como en cualquier parte del mundo, se requiere una gran fuerza política. Es necesaria la conformación de un sujeto político que lo impulse, le dé contenido viable y consiga su aprobación a través de una representación en el poder legislativo. Actualmente no sólo no existe esta fuerza política, sino que la iniciativa ni siquiera es conocida entre la mayor parte de la clase política, menos aun entre la ciudadanía. De manera que la aplicación de un ingreso ciudadano en México tendrá que seguir un camino largo y sinuoso.

De ninguna manera pretendemos analizar la manera en que pueda ser constituida una fuerza político-social que ponga en marcha la aplicación del IC en México. Y no porque desconozcamos la importancia de lo político, sino porque quedafiera de nuestro alcance. Una investigación seria sobre cómo llegar a un acuerdo político-social ameritaría capacidades e instrumentos que están fuera de la ambición de este artículo.

Además, se debe tener en cuenta que la propuesta de ingreso ciudadano en México no se limita a la aprobación de una ley, aunque sea éste un aspecto imprescindible. La propuesta de una renta básica -nombre con el que también se designa al IC- es parte de una estrategia de cambio en el desarrollo socioeconómico del país.

A pesar de ser una iniciativa política de largo plazo, es posible demostrar en términos técnicos (como se hace en este ensayo) que el IC puede ser viable en el corto plazo, con aplicaciones paulatinas y graduales y con repercusiones inmediatas.

La idea general de este artículo se fundamenta en la apreciación de que el libre funcionamiento del mercado tiende a concentrar la producción y la riqueza en pocas manos y, aunque en determinadas condiciones puede mejorar el ritmo de crecimiento económico y ampliar los incentivos para el progreso técnico y la inversión productiva, su libre operación tiende por lo común a concentrar el ingreso nacional y a generar desempleo y subempleo. Para corregir esta tendencia a la concentración del ingreso 
y a la falta de empleos seguros y bien remunerados, es necesaria la intervención del Estado. En este sentido, la función principal del gobierno ha de ser lograr una mejor distribución del ingreso.

Existen otras iniciativas que buscan, mediante políticas de pleno empleo, mejorar las condiciones de vida de la población. Entre ellas destaca la política de Contratista en Última Instancia (CUI), que le da al gobierno la facultad de gastar y utilizar sus instrumentos para contratar personas para cualquier tipo de trabajo y conducir a la economía al pleno empleo. No obstante, no analizaremos esas iniciativas, pues aunque pueden ser complementarias al IC, no se ubican en la misma perspectiva teórica. Compartimos la idea sustancial del CUI: mediante el gasto público es posible alcanzar el pleno empleo en las economías capitalistas actuales. Como ya se mencionó, la propuesta del ingreso ciudadano no excluye la puesta en marcha de políticas de empleo encabezadas por los gobiernos.

\section{El ingreso ciudadano}

El ingreso ciudadano o renta básica se define como la entrega periódica de dinero que el gobierno debe hacer a todos los ciudadanos de un país, por el sólo hecho de residir en él, sin hacer distinción de raza, edad, sexo o religión. Se trata de un subsidio que el gobierno otorga a todos sus ciudadanos, sin importar que cuenten con un empleo o lo estén buscando, si conviven con alguien que lo tiene o si viven solos. La característica más importante de esta subvención es que es incondicional.

La propuesta de un ingreso ciudadano tiene muy diversos orígenes. Aunque con distinta denominación, economistas sobresalientes han apoyado la creación de un subsidio para los ciudadanos que menos tienen o que no tienen nada. Aunque parezca sorprendente, uno de ellos fue Milton Friedman, con su iniciativa de un impuesto negativo, que consiste en el dinero que el gobierno debe entregar a los contribuyentes que declaren un ingreso menor al que se fija para empezar a gravar los ingresos y la riqueza, y cuyo objetivo es igualar, en la base, los ingresos monetarios de todos los declarantes de impuestos. Desde la perspectiva demócrata-liberal de la economía, James Tobin estuvo de acuerdo con una medida como la de Friedman. En Francia, desde posiciones neomarxistas, André Gorz impulsó decididamente la aplicación de una renta básica para reducir los efectos negativos de la sustitución de seres humanos por máquinas en los procesos económicos. No obstante la diversidad de posturas ideológicas de estos investigadores, todos ellos han intentado resolver lo efectos perniciosos de la libre operación de los mercados y la búsqueda de ganancia en el sistema capitalista sobre la distribución del ingreso y el nivel de vida de las mayorías.

Vol. 40, núm. 159, octubre-diciembre / 2009

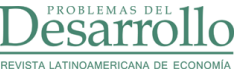


La propuesta del IC busca, entre otras cosas, poner remedio a la pobreza generalizada y a la injusta distribución de la riqueza en el capitalismo, sin llevar a cabo, como tradicionalmente han proclamado los socialistas, un proceso de expropiación de los medios de producción. Dada la experiencia histórica del fracaso de la planificación centralizada en el desarrollo de las fuerzas productivas y el fracaso de la economía de mercado capitalista para conseguir mejorar el nivel de vida de toda la población (supresión de la pobreza), se puede buscar una combinación de eficiencia productiva capitalista con un Estado distribuidor de los éxitos productivos; esto puede conducir a superar la pobreza sin estatizar los medios de producción.

En Holanda, en 1985 se aprobó constitucionalmente un ingreso mínimo para todos sus ciudadanos (16.4 millones de personas) de un monto de US \$ 250 mensuales. Esto representa 7.4\% del PIB de ese país. En Colombia, a los adultos mayores de 60 años (2.6 millones de personas) se les otorgan US \$ 62 mensuales, cuyo monto total alcanza 1.13\% de su PIB (Del Val, 2009).

El IC tiene varias características que habría que tomar en cuenta para su atinada aplicación: 1) como ya se indicó, es incondicional, lo que reduce costos y elimina discriminaciones y usos políticos; 2) sustituye a cualquier otro subsidio estatal (si el ingreso ciudadano es menor, se buscará igualarlo); 3) el monto es una cantidad fija mensual; 4) se financia con impuestos que pueden ser creados ex profeso (por ejemplo, cualquier ingreso monetario superior al ingreso ciudadano se gravaría), ello implica que habrá personas que tributarán una cantidad mucho mayor a lo que recibirán mediante el ingreso ciudadano; 5) todas las actividades económicas que normalmente realizan los ciudadanos se seguirán efectuando y servirán para que quienes más y mejor trabajen, logren aumentar sus ingresos por arriba del mínimo que será el ingreso ciudadano.

Desde el punto de vista de la eficiencia en la asignación de los recursos, los efectos del ingreso ciudadano pueden evaluarse desde el paradigma neoclásico o desde el keynesiano. En cualquier caso, el ingreso ciudadano es una política de redistribución que no afecta para nada el funcionamiento de los mercados, sólo incide sobre la posesión o dotación de recursos con que cuentan las personas. Así, autores neoclásicos tan reconocidos como Hal Varian sostienen:

Desde el punto de vista de la teoría pura, no existe razón alguna por la que el Estado no pueda transferir poder adquisitivo - dotaciones-a los consumidores de la forma que estime oportuna. De hecho, el Estado no necesita transferir las propias dotaciones físicas, sino sólo el poder adquisitivo de las mismas. El Estado puede gravar a cada consumidor en función del valor de su dotación y transferir ese dinero a otro. Si los impuestos se basan en el valor de la dotación de bienes del consumidor, no hay pérdida de eficiencia. (Varian, 1999: 545.) 
De lo anterior se desprende que la tarea impositiva del Estado dirigida a gravar directamente las posesiones, la riqueza o el ingreso monetario de los ciudadanos más opulentos no afecta la eficiencia con que operan los mercados ni la de la economía. Todo seguirá funcionando de manera eficiente independientemente de cómo esté distribuida la riqueza y el ingreso entre los agentes económicos. Por lo cual, concluye Varian refiriéndose a la renta o al ingreso nacional: "Si queremos redistribuirla ¿por qué no simplemente redistribuirla? Si le damos a una persona una peseta [léase euro] adicional, ésta podrá consumir una mayor cantidad de los bienes que desee y no forzosamente del bien subvencionado". (Varian, 1999: 546.) Mejor que los subsidios y los impuestos directos a los bienes y servicios, un impuesto directo al ingreso para ser transferido a los ciudadanos de menores recursos es una acción redistributiva que no afecta negativamente la eficiencia de la economía.

En el marco del paradigma keynesiano, el ingreso ciudadano redistribuye el ingreso y, por tanto, contribuye a elevar la demanda efectiva. Esto último estimula una mayor utilización de los recursos disponibles (capital y trabajo). Adicionalmente, la redistribución del ingreso por ese medio - al contrario de lo que se lograría elevando los salarios- no eleva los costos unitarios de las empresas. Por lo tanto, el ingreso ciudadano no afecta inversamente la competitividad de la producción nacional.

\section{Estimación del costo monetario del ingreso ciudadano en México}

La propuesta para México parte de la idea de que el IC sería el único ingreso libre de impuestos, y el esfuerzo fiscal que se requiere para otorgar este subsidio se orientaría a gravar a los estratos de la población con los ingresos más altos. El impuesto creado ex profeso para cubrir el ingreso ciudadano puede ser un impuesto único, de cierta tasa, tal vez $50 \%$, de todos aquellos ingresos de los contribuyentes que estén por arriba de cierto nivel, o puede ser un impuesto progresivo en la tasa o un impuesto a las ganancias de las empresas ${ }^{1}$.

Existen diversas formas de llevar a la práctica la iniciativa del ingreso ciudadano. En España, por ejemplo, se propone incluir no sólo a los ciudadanos sino a los niños. En Brasil se ha aprobado una iniciativa que entrará en vigor de manera gradual, es decir, cada año se cubrirá un segmento de la población objetivo. Al margen de revi-

1 En México, durante los últimos 25 años, con el pretexto de que las ganancias estimulan la inversión y por tanto el crecimiento económico y el empleo, se han puesto en práctica políticas económicas que favorecen a los perceptores de ganancias. Sin embargo, no se ha observado que este mecanismo funcione, ya que no se ha elevado la inversión.

Vol. 40, núm. 159, octubre-diciembre / 2009 
sar las propuestas de otros países, lo importante es definir cómo podría aplicarse en México y lo que costaría. Para la situación concreta de nuestro país, presentamos tres ejercicios de simulación, sin desconocer que, según las condiciones políticas, también podrían ser viables otras propuestas.

\section{El ingreso ciudadano universal}

La estimación se hará suponiendo que se otorga un ingreso ciudadano equivalente a dos tercios del salario mínimo vigente en la actualidad (2008). Esta propuesta supone que con $\$ 1000$ mensuales (aproximadamente dos tercios del salario mínimo), una familia con la presencia de los dos padres alcanzaría a cubrir el monto máximo que obtiene una familia con el programa Oportunidades. Según información del Programa de Desarrollo Humano Oportunidades, en 2007 el monto máximo de apoyo a las familias con becarios en primaria, secundaria y educación media superior fue de \$1 980 (en caso de que hubiera adultos mayores, esta suma se incrementaría en $\$ 260$ ). De acuerdo con la propuesta, con un ingreso ciudadano de $\$ 1000$ por persona adulta, la familia con dos padres e hijos menores de edad tendría un ingreso ciudadano mensual de $\$ 2000$.

Ahora bien, partamos de que las personas que pueden ser perceptoras del ingreso ciudadano en México son alrededor de 75 millones. De acuerdo con datos del IFE, en julio de 2006, 95\% de la población registrada en el padrón electoral y, por tanto, ciudadano de este país, era de 71351 123, por lo que, se supone, el 100\% de ciudadanos mexicanos serían, aproximadamente, esos 75 millones. Supongamos que a cada persona se le otorga un ingreso ciudadano de \$1 000 mensuales. Al año serían $\$ 12000$ por persona, que al multiplicarlos por el total de personas que recibirían este subsidio, darían un monto total de $\$ 900000$ millones, que es lo que se requeriría para cubrir el ingreso ciudadano universal en México. Esta cantidad es aproximadamente entre 9\% y $10 \%$ del Producto Interno Bruto (PIB), lo que nos lleva a pensar, dado que actualmente se recauda $11 \%$ del PIB como impuestos (excluyendo el petróleo), que la recaudación tributaria que se necesita para hacer efectiva la aplicación del ingreso ciudadano en México, debería duplicarse. Con el propósito de no afectar otras partidas del presupuesto gubernamental, la meta recaudatoria debería ser, como mínimo, $20 \%$ del PIB.

Al hacer una estimación cuantitativa de la repercusión de este subsidio sobre las principales variables macroeconómicas (PIB y empleo), se obtienen resultados muy positivos. En el entendido de que en México, del total del ingreso nacional, alrededor de $70 \%$ se dirige al consumo privado, y suponiendo que la propensión marginal al con- 
sumo es igual a uno, de esos $\$ 900000$ millones, cateris paribus, un poco más de $\$ 600000$ millones se destinarían al consumo privado, y ello repercutiría en el PIB, elevándolo $6 \%$. Con una tasa de crecimiento de esa magnitud y suponiendo que la productividad del trabajo se incrementara en 2.7\%, como ocurrió en el periodo 1970-1981 (López, 2008: 177), el incremento en el empleo sería superior a tres por ciento.

\section{El ingreso ciudadano por tipo de familias}

Otra forma de hacer una estimación sobre el costo del ingreso ciudadano en México es tomar en cuenta los tipos de familias u hogares que existen en el país. Una buena aproximación se puede encontrar en el ensayo "Por un ingreso ciudadano universal: pertinencia y factibilidad política para México" (Marrufo y Moreno, 2008), incluido en el libro El derecho a la existencia y la libertad real para todos.

Partiendo de datos del INEGI (2007), los autores construyeron un cuadro estadístico suponiendo que en México existen tres clases de hogares: unipersonal, nuclear y no nuclear. Unipersonal es un hogar de una sola persona; nuclear es un hogar compuesto por el jefe, su cónyuge y los hijos, y los hogares no nucleares se componen del jefe, su cónyuge, los hijos y otros parientes.

Para 2007, el INEGI estimaba un población total de 104860000 personas, y el PIB se calculó, para el año 2006, en 9 billones 377 mil 157 millones de pesos. En concreto, la propuesta consiste en que a cada tipo de hogar se le entregue al mes $\$ 500, \$ 700$ y $\$ 1000$, respectivamente (véase cuadro 1 ).

Cuadro 1

Financiamiento del ingreso ciudadano por tipo de hogar

\begin{tabular}{|c|c|c|c|c|c|}
\hline Hogares & Cantidad & Pago por mes en pesos & Pago anual en pesos & $\begin{array}{c}\text { Pago total en miles } \\
\text { de pesos }\end{array}$ & \% del PIB 2006 \\
\hline No nuclear & 5457074 & 1000 & 12000 & 65484880 & $0.70 \%$ \\
\hline Nuclear & 15294405 & 700 & 8400 & 128473002 & $1.37 \%$ \\
\hline & 1403179 & 500 & 6000 & 8419074 & $0.09 \%$ \\
\hline Unipersonal & & & & & $202 \mathbf{3 7 6} 956$ \\
\hline Total & 22154658 & & & $2.16 \%$ \\
\hline
\end{tabular}

Fuente: Moreno y Marrufo, 2008. 
Como se puede observar, para financiar este tipo de ingreso ciudadano en México, se requeriría al año sólo $2.16 \%$ del PIB.

Efectuando el mismo ejercicio que en el apartado anterior, el impacto de este aumento de más de $\$ 200000$ millones en el ingreso de la población, suponiendo que la propensión marginal a consumir es igual a uno y que los precios no varíen, sería el siguiente: el PIB tendría un incremento de $1.5 \%$ y, tomando como referencia el periodo 1982-1994 (en que la economía mexicana creció a esa tasa) (López, 2008: 177), el empleo crecería en un 0.9 por ciento.

\section{El ingreso ciudadano para la población más vulnerable}

Una tercera opción para aplicar el ingreso ciudadano en México es incorporar al programa a la población más vulnerable del país. Esto se podría hacer con el pago de una pensión universal a los adultos mayores (como ya se hace en el Distrito Federal) y un pago mensual a todos los niños menores de 15 años. Así, se podría empezar el programa dándole prioridad a la población con mayores desventajas sociales.

Según el INEGI, los habitantes de México que tienen más de 60 años son 8.2 millones, y la población de menos de 15 años es de 31.7 millones.

Cuadro 2

Financiamiento del ingreso ciudadano a la población más vulnerable

\begin{tabular}{|c|c|c|c|c|c|}
\hline & Millones & $\begin{array}{l}\text { Pago mensual } \\
\text { en pesos }\end{array}$ & $\begin{array}{c}\text { Pago anual } \\
\text { en pesos }\end{array}$ & $\begin{array}{c}\text { Pago total millones } \\
\text { de pesos }\end{array}$ & $\begin{array}{l}\% \text { del PIB } \\
\text { en } 2006\end{array}$ \\
\hline $\begin{array}{c}\text { Adultos mayores } \\
\text { de } 60 \text { años }\end{array}$ & 8.2 & 1000 & 12000 & 98400 & 1.05 \\
\hline $\begin{array}{r}\text { Niños menores } \\
\text { de } 15 \text { años }\end{array}$ & 31.7 & 600 & 7200 & 228240 & 2.43 \\
\hline Total & 49.9 & & & 326640 & 3.48 \\
\hline Menores de 20 años & 41.7 & & 7200 & 300240 & 3.20 \\
\hline $\begin{array}{l}\text { Adultos entre } \\
50 \text { y } 60 \text { años }\end{array}$ & 7.21 & 1000 & 12000 & 86520 & 0.92 \\
\hline
\end{tabular}

Fuente: elaboración propia con datos del II Conteo de Población y Vivienda 2005, INEGI.

Se han tomado los pagos mensuales de $\$ 1000$ y $\$ 600$ porque según el Consejo Nacional de Evaluación de la Política Social, en el sector rural se encuentran en pobreza alimentaria aquellos que obtienen ingresos mensuales menores a $\$ 584.34$, y en pobreza patrimonial los que obtienen menos de $\$ 1060.34$. De acuerdo con estos resultados, se necesitaría, aproximadamente, $3.5 \%$ del PIB para poner en marcha el 
programa. En el segundo año, suponiendo que se incorporaran al ingreso ciudadano los jóvenes de entre 15 y 20 años, se tendría que tomar en cuenta a 10 millones de personas más, según datos del II Conteo de Población y Vivienda 2005. Si suponemos que se les otorgara un ingreso ciudadano de $\$ 600$, ello significaría $4.25 \%$ del PIB. Si al tercer año se incorporaran al programa las personas de entre 50 y 60 años, es decir, 7.21 millones de personas más, se agregaría $0.92 \%$ del PIB, con lo que el monto total que se destinaría al ingreso ciudadano sería $5.17 \%$ del PIB.

Con este tipo de ingreso ciudadano, en tres años, con alrededor de 5\% del PIB que se distribuyera a través del programa, se cubrirían las necesidades alimenticias de los menores de 20 años y las necesidades básicas de los mayores de 50 años.

\section{Repercusiones macroeconómicas del ingreso ciudadano en México}

En México, y seguramente en otros países, la aplicación de políticas económicas que mejoren la distribución del ingreso ha concitado fuertes y encontradas polémicas. Cuando los objetivos económicos se centran en la estabilidad macroeconómica, las medidas encaminadas a redistribuir el ingreso son consideradas impropias e impertinentes. Según los cánones de la corriente económica principal (el mainstream), la política social, no la económica, es la encargada de buscar soluciones o paliativos para la pobreza y marginación provocadas por el funcionamiento del mercado. De acuerdo con esta perspectiva, la política social debe encargarse de ayudar a quienes no están capacitados para competir en el libre mercado. Sin embargo, ya se señaló que desde la perspectiva keynesiana, tanto la política social como la económica son complementarias, ya que aquélla contribuye a ampliar la demanda y, con ello, la utilización de los recursos.

La situación crítica a la que se enfrentan quienes no pueden obtener un empleo formal, seguro y estable, así como las tendencias de largo plazo que han elevado el porcentaje de la población dedicada al empleo informal, sugieren que una política social es insuficiente para resolver los problemas de desempleo, subempleo, pobreza, marginación y lento crecimiento de la economía. Por ello, se propone una política de redistribución del ingreso mediante el ingreso ciudadano o renta básica. La pregunta por contestar en este apartado es: ¿cuáles serán los efectos de una política de ingreso ciudadano sobre el crecimiento, la estabilidad y el bienestar de la población en México? Como es evidente, el primer efecto se produce sobre el gasto gubernamental. Para hacer frente al pago de un ingreso ciudadano, el gobierno debe aumentar sus ingresos: ¿cómo financiar el aumento en el gasto gubernamental?

Vol. 40, núm. 159, octubre-diciembre / 2009 
Desde una perspectiva macroeconómica, el gasto de gobierno puede financiarse de tres maneras: 1) gravando a la población en general, por ejemplo mediante el IVA; 2) a través de deuda gubernamental, mediante bonos o emisión de dinero (gasto deficitario), y 3) gravando las ganancias de las empresas.

La primera opción queda descartada, ya que no se pretende gravar a quienes reciben menos ingresos.

La segunda influye sobre la expansión de la demanda sin que se restrinja o reduzca el ingreso de ningún sector de la población. Ello ocasiona el aumento de las ganancias empresariales y, por tanto, es un medio que no contribuye a solucionar el problema de la enorme concentración de riqueza, precisamente uno de los obstáculos que se pretende eliminar. Es decir, la deuda gubernamental provoca el efecto contrario al deseado, que es una distribución más equitativa del ingreso.

Por tales razones, la tercera opción es la más viable para propósitos redistributivos. Esto se afirma al circunscribirnos al ámbito económico y se confirma en la esfera social: los beneficiarios de esta política son los estratos de más bajos ingresos; aunque la viabilidad de la medida se ve obstaculizada cuando se analiza la esfera política. Enseguida se revisarán las consecuencias económicas de la aplicación de un ingreso ciudadano en México, es decir, los efectos macroeconómicos de un aumento de los impuestos a las ganancias del capital.

Supongamos que las dificultades políticas para aprobar un impuesto de esta naturaleza han sido superadas. ¿Cuál sería entonces el impacto de un gravamen a las ganancias de las empresas sobre la estabilidad económica de México?

Como se ha insistido, la redistribución del ingreso a favor de los estratos más desfavorecidos generará un efecto positivo sobre la demanda agregada. Elevar los ingresos de amplias capas de la población aumentará su poder adquisitivo y, por ende, la demanda de bienes y servicios de consumo familiar. Es decir, por esta vía crece la demanda de los hogares y por tanto se incrementa el consumo privado de bienes y servicios finales. Este incremento de demanda puede abastecerse en el corto plazo (uno o dos años), mediante la mayor utilización de la capacidad de la planta productiva instalada. Sin embargo, después de un tiempo, la demanda podría exceder a la oferta y ocasionar un aumento de precios. Lo mismo ocurriría de manera inmediata en los sectores productivos que no tengan capacidad para incrementar su oferta en el corto plazo.

Es decir, el aumento de la demanda puede presionar a los precios al alza, si se supone que se está trabajando a plena capacidad en todas las empresas y que las ganancias de las empresas tienden a bajar. Este escenario de inestabilidad inflacionaria supone que los precios varían porque el aumento de la demanda es mayor al de la oferta. Sin embargo, no está descartada la hipótesis de que en los mercados oligopólicos que existen 
en la economía mexicana, los precios puedan variar por políticas de las empresas, sin que éstas estén al límite de uso de su capacidad. Así, una empresa que tenga capacidad productiva ociosa, puede aumentar sus precios por el hecho de saber que el poder adquisitivo de los consumidores se ha incrementado, aunque en principio podría hacer frente a esa mayor demanda con un uso mayor de su capacidad productiva instalada o, en el mediano plazo, con ampliaciones programadas en su capacidad productiva.

Por otro lado, también puede preverse un impacto sobre la inversión privada. Si la ganancia por unidad producida después del impuesto para financiar el ingreso ciudadano se reduce, esto puede compensarse con el aumento de la ventas; pero aun así, debemos tomar en cuenta que las decisiones de inversión no sólo dependen de las ganancias corrientes, sino que tienen que ver con variables no económicas. Dado que la inversión privada en México es efectuada en su mayor parte (65\%) por las empresas más grandes (según el último censo económico las unidades empresariales que emplean a 500 o más personas son 2665 ), es posible que los dirigentes de estas empresas, como lo han hecho en otras ocasiones, tengan una reacción más política. Es decir, habría que considerar que la inversión privada en México, al estar tan concentrada en pocas empresas, no sólo depende de variables económicas, sino que muchas veces se maneja políticamente. Ello sugiere que habría que realizar pactos políticos para sostener y estimular la inversión privada.

En el plano externo, dada la apertura de la economía mexicana, el incremento de la demanda de bienes y servicios ocasionará un aumento de las importaciones que puede hacer crecer el déficit externo. Si la demanda doméstica se expande, las importaciones crecen y las exportaciones podrían disminuir por el alza en la demanda interna; esto, en su conjunto, incrementaría el déficit comercial.

En suma, esta iniciativa de ingreso ciudadano puede producir inestabilidad macroeconómica, tanto interna como externa, pero se espera que pueda ser controlada mediante una amplia negociación política y en caso de que la aplicación del ingreso ciudadano se haga de manera gradual. De todas formas, a pesar de que los acuerdos políticos son clave, el ingreso ciudadano debe acompañarse de otras medidas de política económica para reducir sus efectos adversos.

\section{¿Cómo enfrentar la inestabilidad interna y externa?}

En términos de la actividad económica, es claro que la redistribución del ingreso provocará que algunos empresarios incrementen sus ganancias y otros las disminuyan. Lo que el gobierno debe cuidar es el posible efecto de la redistribución sobre

Vol. 40, núm. 159, octubre-diciembre / 2009

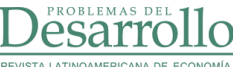


la inversión privada. Ésta requiere un tratamiento especial para que desempeñe su función dinamizadora de la economía. El gobierno y los promotores de la iniciativa del ingreso ciudadano, así como los sectores beneficiados por su aplicación, deberían hacer hincapié en que no se trata de una lucha contra el capital, sino a favor del mismo, y que la libertad de los mercados no se verá mermada, al contrario, la empresa privada y el libre funcionamiento de los mercados se verán estimulados y expandidos. En otras palabras, deberá quedar claro para todos que con la medida propuesta “...no se aboga francamente por un sistema de socialismo de Estado que abarque la mayor parte de la vida económica de la comunidad. No es la propiedad de los medios de producción la que conviene al Estado asumir. Si éste es capaz de determinar el monto global de los recursos destinados a aumentar esos medios y la tasa básica de remuneración de quienes los poseen, habrá realizado todo lo que le corresponde" (Keynes, 1986: 333). Es decir, el gobierno debe ser capaz de determinar la inversión agregada de la economía, pues ésta es la única forma de acrecentar el capital y aproximarse a un funcionamiento estable de la economía. Ello se logrará cuando el Estado intervenga para determinar la tasa de ganancia básica (remuneración a los poseedores de los medios de producción) de todas las empresas. Es decir, el Estado debe intervenir directamente en la fijación de la inversión agregada bruta de la economía y, por tanto, en la regulación de la tasa de ganancia, para asegurar que el ingreso ciudadano no conlleve la retracción de la inversión privada.

La inversión privada puede reaccionar negativamente (por razones políticas) frente a la iniciativa del ingreso ciudadano, pero la única manera de evitar su retraimiento y ocasionalmente la fuga de capitales es que el gobierno diseñe una estrategia para tener en sus manos la determinación del "monto global de los recursos destinados a aumentar" los medios de producción; la manera de conseguirlo es a través de un política fiscal que sea aplicada gradualmente, y que además sea concertada y pactada.

La determinación del monto global de los recursos destinados a aumentar los medios de producción está directamente vinculada al crecimiento económico. La expansión de la demanda de bienes de consumo final que suscitará el ingreso ciudadano, debería ser acompañada por un incremento de las ganancias de los sectores que producen esos bienes, y esto debería aumentar las inversión productiva en esos sectores. A su vez ello debería estimular la actividad de los sectores que producen los medios de producción. En términos de economía pura, la expansión de la demanda de bienes de consumo final va a ser acompañada de una ampliación de la oferta de bienes de inversión; pero en términos de economía política, el gobierno debe negociar y tomar medidas complementarias a la del ingreso ciudadano. 
En un ejercicio sobre los requerimientos de inversión para que México logre alcanzar tasas de crecimiento más elevadas, Julio López (1998) muestra que para obtener una tasa uniforme de 6\% del producto al año durante un periodo de 15 años (2000-2015), se necesita una tasa de inversión (proporción de la inversión en el producto) que empezando con $20 \%$ en los primeros años, no pase de $25 \%$ en el último. Lo que significa que los esfuerzos de financiamiento de la inversión, meta obligada del gobierno, no tienen que ser demasiado fuertes, pues en la actualidad se sabe que esta participación se encuentra en alrededor de 20\%. Para desarrollar esta estrategia, López sostiene que deben emplearse las capacidades productivas que están ociosas, lo cual "se traduce también en un crecimiento del empleo formal más rápido y en un más veloz crecimiento de la tasa de empleo formal" (López, 1998: 225). Esto último reforzaría la demanda de bienes de consumo y en términos agregados se establecería un círculo virtuoso entre el crecimiento de la producción y la expansión de la demanda.

Si se obtienen estas relaciones económicas al interior de la economía, el problema que se va a presentar es el límite al crecimiento que impone el sector externo. De acuerdo con la Ley de Thirlwall, la tasa potencial de crecimiento económico de un país no sólo está determinada por la disposición interna de recursos, sino por el ritmo de crecimiento de las exportaciones y la elasticidad ingreso de las importaciones. Según este autor, la expansión de cualquier economía está limitada por el sector externo: entre mayor sea la capacidad de exportación y menor la tendencia a importar, este límite se expandirá. En este sentido, el crecimiento económico que puede traer consigo la aplicación de una política de renta básica y, por añadidura, el posible crecimiento del déficit externo impulsado por la expansión de la demanda doméstica, sólo puede reducirse mediante una política de fomento a las exportaciones y de sustitución de importaciones.

Dados los objetivos limitados de este trabajo, no podemos discutir aquí todos los elementos que deberían contemplarse en una estrategia de crecimiento. Diremos tan sólo que en México, la mayor parte del comercio exterior es de bienes manufacturados, por lo que lo más indicado sería el diseño y aplicación de una política industrial que se base en las ventajas comparativas potenciales del sector. La idea es que la especialización productiva en lo que el país mejor sabe hacer y en lo que produce de manera más eficiente, redundará en un mayor crecimiento económico en condiciones de equilibrio externo. Esta política económica puede ser sustentada en cualquier criterio de ordenación que evalúe estas ventajas comparativas (no necesariamente competitivas). Una posible medición se realiza a través del costo doméstico de la divisa (CDD) o costo doméstico de los recursos (CDR) (Schydlowsky, 1990).

Vol. 40, núm. 159, octubre-diciembre / 2009 
El CDD es la estimación de cuánto le cuesta al país producir un dólar considerando los costos y beneficios sociales. Con este cálculo se pueden ordenar las actividades productivas de menor a mayor costo y de esa manera priorizar la atención, mediante una política industrial, en las actividades productivas con menor costo y mayor ventaja comparativa potencial. Esta política consistiría en el fomento de aquellos sectores que observen mayor capacidad de competencia en el mercado mundial y en la búsqueda de la sustitución de importaciones que reduzcan la elasticidad ingreso de las compras en el exterior. Las presiones sobre el sector externo se podrían reducir con la creación de una estrategia de generalización del ingreso ciudadano.

En suma, la aplicación de una medida como el ingreso ciudadano en México es posible, y puede ser importante tanto por razones sociales como económicas. Pero tendría que ser acompañada de una política de inversión global guiada por el gobierno y de una política de especialización productiva que inserte a la economía mexicana en la competencia internacional con mejores perspectivas.

\section{Bibliografía}

Cortés, Fernando, La distribución del ingreso en México en épocas de estabilización y reformas económicas, México, CIESASPorrúa, 2000.

Del Val, Enrique, "Una propuesta de Ingreso Ciudadano Universal para México", presentación ante la Academia Mexicana de Economía Política, 2009.

Gorz, André, Miserias del presente, riqueza de lo posible [trad. Cristina Piña], Buenos Aires, Paidós, 2003.

Keynes, John M., Teoría general de la ocupación, el interés y el dinero, México, FCE, 1986.

Lajouos, Andrés, "Santiago Levy: Hacia una seguridad social para todos", en Nexos, núm. 377, México, mayo de 2009.

Levy, Santiago, Good Intentions, Bad Outcomes: Social Policy, Informality and Economic Growth in Mexico, Washington DC, Brookings Institution Press, 2008.

López Gallardo, Julio, La economía de Michal Kalecki y el capitalismo actual, México, FCE, 2008.

, La macroeconomía de México: el pasado reciente y el futuro posible, México, UNAM-Miguel Ángel Porrúa, 1998.

Marrufo, Eduardo y Pedro Moreno, "Por un ingreso ciudadano universal: pertinencia y factibilidad política para México", en Pablo
Yanes (coord.), El derecho a la existencia y libertad real para todos, México, Universidad Autónoma de la Ciudad de MéxicoSecretaría de Desarrollo Social del Gobierno del DF-Grupo Promotor del Ingreso Ciudadano, 2007.

Pinilla, Rafael, "La renta básica en el contexto de la reforma fiscal. Principales disyuntivas", comunicación preparada para el X Encuentro de Economía Pública, Tenerife, 6 y 7 de febrero de 2002. Disponible en: http://www.nodo50.org/redrentabasica/ descargas/basica0XEEP.pdf

Raventós, Daniel, Las condiciones materiales de la libertad, Barcelona, El Viejo Topo, 2007.

Raventós, Daniel (coord.), La renta básica. Por una ciudadanía más libre, más igualitaria y más fraterna, Barcelona, Ariel, 2002.

Schydlowsky, Daniel, "La eficiencia industrial en América Latina: mito y realidad", Pensamiento iberoamericano. Revista de economía política, núm. 16, Madrid, Sociedad Estatal Quinto Centenario, 1990, pp. 131166.

Varian, Hal, Microeconomía intermedia: un enfoque actual [trad. Ma. Esther Rabasco y Luis Toharia], Barcelona, Antoni Bosch editor, 1999.

Vol. 40, núm. 159, octubre-diciembre / 2009 